\title{
Effects of acute gamma irradiation on soil invertebrates in laboratory tests
}

\author{
T. Nakamori ${ }^{1}$, Y. Kubota ${ }^{1}$, T. Ban-nai ${ }^{1}$, Y. Fujii ${ }^{2}$ and S. Yoshida ${ }^{1}$ \\ ${ }^{1}$ National Institute of Radiological Sciences, Chiba 263-8555, Japan \\ ${ }^{2}$ Yokohama National University, Yokohama 240-8501, Japan
}

\begin{abstract}
An understanding of the dose-effect relationships of ionising radiation for nonhuman biota establishes important baselines for the radiological protection of ecosystems. We used standard laboratory tests to examine the dose-effect relationships of gamma radiation on the survival, growth and reproduction of the earthworm, Eisenia fetida (Oligochaeta). Adult E. fetida were acutely irradiated with increasing doses of gamma radiation, and the subsequent survival, growth in wet weight and number of offspring were examined. The $50 \%$ lethal dose $\left(\mathrm{LD}_{50}\right)$ was $825 \mathrm{~Gy}$, and the $10 \%$ and $50 \%$ effective doses $\left(\mathrm{ED}_{10}\right.$ and $\left.\mathrm{ED}_{50}\right)$ for growth were 20.2 and $94.7 \mathrm{~Gy}$, respectively. The $\mathrm{ED}_{10}$ and $\mathrm{ED}_{50}$ for reproduction were 3.3 and $11.1 \mathrm{~Gy}$, respectively.
\end{abstract}

\section{INTRODUCTION}

The radiological protection of the environment based on scientific principles is an important environmental safety concern [1]. The International Commission on Radiological Protection (ICRP) requires the effect data of ionising radiation on nonhuman biota for the radiological protection of the environment [1]. An understanding of the dose-effect relationships establishes important baselines for the radiological protection of ecosystems.

Soil processes are vital to sustainable terrestrial ecosystems, and soil invertebrates play an important role in nutrient cycling by feeding on microbiota. Given their ecological importance, soil invertebrates are used for ecological impact assessments of terrestrial ecosystem pollutants. Single-species laboratory tests are used to understand the toxicity of chemicals and to extrapolate the sensitivity of diverse species in a community. Standard tests using earthworms and springtails have been developed by the Organisation for Economic Co-operation and Development (OECD) and the International Organisation for Standardisation (ISO) [2]. Similar protocols are also useful for assessing radiation effects.

This study examined the dose-effect relationships of radiation for soil invertebrates. Recently, we applied standard test protocols to examine the dose-effect relationships of gamma radiation on survival and reproduction in the springtail Folsomia candida (Collembola) [3]. Here, we present the results of tests on the earthworm, Eisenia fetida (Oligochaeta), and compare the sensitivities of soil invertebrates to gamma radiation.

\section{MATERIALS AND METHODS}

\subsection{Animals}

Earthworms (E. fetida) were obtained from a commercial source for composting (Sagami Joka Service, Japan). Stock cultures were reared on wheat bran in plastic containers $(26 \times 38 \mathrm{~cm}$ bottom, $24 \mathrm{~cm}$ height) with moist peat moss as the culture substrate $\left(5 \mathrm{~cm}\right.$ depth; $\mathrm{pH} 6.0$ adjusted with $\left.\mathrm{CaCO}_{3}\right)$ in a climate-controlled room $\left(20^{\circ} \mathrm{C}\right)$ under a $16: 8 \mathrm{~h}$ light : dark regime. Age-synchronised worms used in experiments were prepared according to the OECD [4]. 


\subsection{Toxicity tests}

Earthworm reproduction tests were carried out largely according to the OECD [4]. Reproductive success (number of offspring per test vessel) and growth in wet weight (average of individual worms in a test vessel) were measured. Seven-month-old earthworms with a clitellum were placed in glass containers with a small amount of water and allowed to defecate for 1 day; their wet weights were measured after removing the excess water using filter paper. A group of ten worms (average wet weight ca. $400 \mathrm{mg}$ ) was transferred to a plastic Petri dish with moist filter paper and then acutely irradiated with $0,4,8,12,24$, 40,72 or $128 \mathrm{~Gy}$ of ${ }^{137} \mathrm{Cs}$ gamma radiation. After irradiation, the worms were reared in polyethylene test containers (11 cm diameter, $11 \mathrm{~cm}$ high; polyethylene lid with small holes) with $400 \mathrm{~g}$ (wet weight) of OECD artificial soil (peat moss : kaolin clay : sand $=10: 20: 70$ by dry weight; $\mathrm{pH} 6.0$ adjusted with $\left.\mathrm{CaCO}_{3}\right)$ in a climate-controlled room $\left(20^{\circ} \mathrm{C}\right)$ under a $16: 8 \mathrm{~h}$ light: dark regime. Air-dried wheat bran $(3 \mathrm{~g})$ with water $(5 \mathrm{ml})$ was supplied as food on the soil surface of each test vessel and replaced weekly. Mass losses in the test vessels were recovered by adding water to keep soil moisture content constant. Four weeks after irradiation, the adult worms were removed from the soil, placed in glass containers $(50 \mathrm{~mm}$ diameter, $55 \mathrm{~mm}$ high) with a small amount of water and allowed to defecate for 1 day; their wet weights were measured after removing any excess water using filter paper. An additional $3 \mathrm{~g}$ of food with $5 \mathrm{ml}$ of water was placed on the soil surface of each test vessel and then no food was supplied. Eight weeks after irradiation, the number of offspring (hatched from the cocoons) in the soil was examined by hand collecting. Eight replicates of nonirradiated controls were used, with four for each treatment.

Earthworm survival tests were carried out largely according to the OECD [5]. Adult worms with a clitellum (wet weight ca. $500 \mathrm{mg}$, age not specified) were treated as in the reproduction tests, except that higher doses of ${ }^{60} \mathrm{Co}$ gamma radiation $(0,70,130,240,415,745,1330$ or $1775 \mathrm{~Gy})$ were used; survival was examined 2 weeks after irradiation. No food was supplied and the test was conducted in continuous light. Four replicate vessels were used per dose radiation and non-irradiated control.

\subsection{Statistics}

The data were analysed as described elsewhere [3]. Briefly, a logistic model was used to estimate the effect parameters: the $50 \%$ lethal dose $\left(\mathrm{LD}_{50}\right)$ and the $10 \%$ and $50 \%$ effective doses $\left(\mathrm{ED}_{10}\right.$ and $\mathrm{ED}_{50}$, respectively). The treatment means were used for the regression analysis. One-way analysis of variance (ANOVA) and Dunnett's comparison with the control at a 5\% significance level were performed to determine the no-observed-effect and lowest-observed-effect doses.

\section{RESULTS AND DISCUSSION}

Laboratory toxicity tests were applied to examine the dose-effect relationships for acute gamma irradiation of the earthworm, E. fetida. The OECD criteria for a validation test [4] were met in this study: in reproduction test controls, adult mortality was $3 \%$, the average number of offspring per vessel was 150.3 and the coefficient of variation of offspring was $18.3 \%$.

Figure 1 shows the dose-effect relationships of acute gamma irradiation for the reproduction, growth and survival of E. fetida. Reproduction and survival showed clear dose-effect relationships, but growth did not. This may have been partly due to technical reasons, such as inconsistent removal of water and gut loads at weighing. Higher reproduction at lower doses may also obscure the dose-effect relationships on growth in weight, since reproduction may reduce the weight of worms.

The no-observed-effect and lowest-observed-effect doses of acute gamma irradiation for reproduction were 4 and $8 \mathrm{~Gy}$, respectively (ANOVA, $P<0.05$ ). The $\mathrm{ED}_{10}$ and $\mathrm{ED}_{50}$ for reproduction and the $\mathrm{LD}_{50}$ of acute gamma irradiation were 3.3,11.1 and $825 \mathrm{~Gy}$, respectively (Table 1). The value of $\mathrm{LD}_{50}$ was higher than that in Suzuki and Egami [6] (650 Gy), probably because of the longer test period 
in their study ( 4 weeks) compared to ours ( 2 weeks), as the mortality of irradiated animals increases with time $[3,6]$.

The sensitivity of reproduction to acute gamma irradiation was greater than that to chronic irradiation in the earthworm reproduction test. In external chronic exposure tests, the hatchability of cocoons produced during the first 4 weeks decreases by $61 \%$ at $43 \mathrm{~m} \mathrm{~Gy} / \mathrm{h}$ (accumulated dose of $26 \mathrm{~Gy}$ ) [7]. The $\mathrm{ED}_{50}$ for reproduction with acute irradiation $(11.1 \mathrm{~Gy})$ was approximately half of the accumulated dose. Since effect data for chronic exposure are limited, standard laboratory tests are useful for extrapolating from acute toxicity to chronic toxicity in radioecology. However, extrapolation has a limitation, since chronic exposure for a longer period than the standard test have more severe or different effects [7].
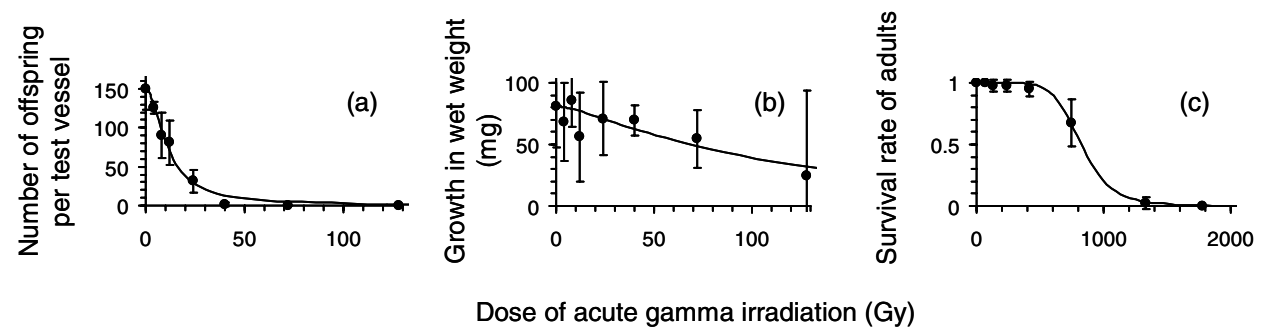

Figure 1. Effects of acute gamma irradiation on reproduction (a), growth (b) and survival (c) in Eisenia fetida. Reproduction, growth in wet weight and survival were examined 8, 4 and 2 weeks after irradiation, respectively. Survival was examined in a different series of assays. The data points are the averages of replicates $(n=8$, nonirradiated control for reproduction and growth test; $n=4$, others). Error bars indicate the standard deviation. The lines are dose-response relationships fitted using a logistic model.

Table 1. Effective doses (Gy) of acute gamma irradiation for soil invertebrates.

\begin{tabular}{|l|c|c|c|c|c|c|}
\hline \multirow{2}{*}{ Animals } & \multicolumn{2}{|c|}{ Reproduction } & \multicolumn{2}{c|}{ Growth } & Survival & \multirow{2}{*}{ References } \\
\cline { 2 - 6 } & $\mathrm{ED}_{10}$ & $\mathrm{ED}_{50}$ & $\mathrm{ED}_{10}$ & $\mathrm{ED}_{50}$ & LD $_{50}$ & this work \\
Earthworm & 3.3 & 11.1 & 20 & 95 & 825 & \\
fetisenia & $(2.1-4.8)$ & $(9.3-13.1)$ & $(0.4-80)$ & $(53-1516)$ & $(\mathrm{NA}-865)$ & \\
\hline Springtail & $(8$ weeks $)$ & $(8$ weeks $)$ & $(4$ weeks $)$ & $(4$ weeks $)$ & $(2$ weeks $)$ & \\
$($ Folsomia & 7.1 & 21.9 & 32 & 144 & 1356 & {$[3]$} \\
candida $)$ & $(4.0-11.3)$ & $(17.5-27.1)$ & $(13-52)$ & $(98-187)$ & $(1343-1368)$ & \\
\hline
\end{tabular}

$\mathrm{ED}_{\mathrm{x}}, \mathrm{x} \%$ effective dose; $\mathrm{LD}_{50}, 50 \%$ lethal dose; first parentheses, $95 \%$ confidence interval; second parentheses, test period; NA, not available. Growth was measured in wet weight and body length for earthworms and springtails, respectively.

Table 1 summarises the effective doses of acute gamma irradiation for soil invertebrates (the earthworm E. fetida and the springtail F. candida) derived from standard toxicity tests. In the standard tests, E. fetida was more sensitive than $F$. candida, although differences exist in the life span and experimental design between the animals. A higher sensitivity of E. fetida than $F$. candida is also observed for heavy metals [e.g., 8], but not for certain organic chemicals, such as insecticides [e.g., 9]. Reproduction was more sensitive to gamma radiation than survival in both E. fetida and F. candida. The higher sensitivity of reproduction is consistent with findings in other invertebrates [e.g., 10]. This may be explained by the fact that reproductive tissues, which require mitotic activity, are more sensitive to ionising radiation than other tissues.

Laboratory toxicity tests are also applicable in field contamination monitoring, if test organisms have been exposed to field-collected soils. In such assays, increased attention has focused on gene expression as a biomarker, as it may allow fast, sensitive and diagnostic assays [11]. However, limited 
sequence information for ecotoxicological species hampers such applications. Recently, we applied a novel technology, high-coverage expression profiling (HiCEP) [12], to detect radiation responsive genes as a biomarker in soil invertebrates. HiCEP is useful not only for identifying radiation-induced genes after genome-wide screening even in organisms with limited prior sequence knowledge, but also for revealing dose-dependent gene expression [13].

\section{Acknowledgments}

This study was supported by the NIRS (Japan) president's initiative. We thank Y. Watanabe (NIRS, Japan) and S. Fuma (NIRS, Japan) for helpful suggestions.

\section{References}

[1] ICRP, Publication 91. A Framework for Assessing the Impact of Ionising Radiation on Non-human Species. Ann ICRP 33 (2003).

[2] Jänsch S., Amorim M.J. and Römbke J., Environ. Rev. 13 (2005) 51-83.

[3] Nakamori T., Yoshida S., Kubota Y., Ban-nai T., Kaneko N., Hasegawa M. and Itoh R., Ecotoxicol. Environ. Saf. doi: 10.1016/j.ecoenv.2007.10.029.

[4] OECD, Guideline for Testing Chemicals 222. Earthworm Reproduction Test (Eisenia fetida/Eisenia andrei) (OECD, Paris, 2004).

[5] OECD, Guideline for Testing of Chemicals 207. Earthworm Acute Toxicity Tests (OECD, Paris, 1984).

[6] Suzuki J. and Egami N., J. Radiat. Res. 24 (1983) 209-220.

[7] Hertel-Aas T., Oughton D.H., Jaworska A., Bjerke H., Salbu B. and Brunborg G., Radiat. Res. 168 (2007) 515-526.

[8] Kuperman R.G., Checkai R.T., Smini M. and Phillips C.T., Ecotoxicol. Environ. Saf. 57 (2004) 48-53.

[9] Lock K., De Schamphelaere K.A.C. and Janssen C.R., Arch. Environ. Contam. Toxicol. 42 (2002) 217-221.

[10] Watanabe M., Sakashita T., Fujita A., Kikawada T., Horikawa D.D., Nakahara Y., Wada S., Funayama T., Hamada N., Kobayashi Y. and Okuda T., Int. J. Radiat. Biol. 82 (2006) 587-592.

[11] Ankley G.T., Miracle A.L., Perkins E.J. and Daston G.P. Eds., Genomics in Regulatory Ecotoxicology (CRC Press, Boca Raton, 2007).

[12] Fukumura R., Takahashi H., Saito T., Tsutsumi Y., Fujimori A., Sato S., Tatsumi K., Araki R. and Abe M., Nucleic Acids Res. 31 (2003) e94.

[13] Nakamori T., Fujimori A., Kinoshita K., Ban-nai T., Kubota Y. and Yoshida S., Environ. Sci. Technol. (in press). 